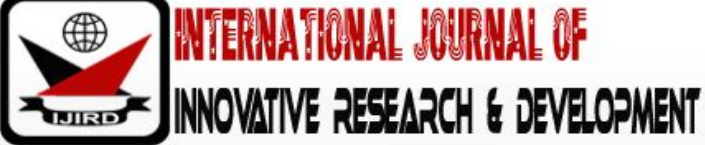

ISSN 2278 - 0211 (Online)

\section{Effects of School Quality Assurance Communication Officers' Feedback in Improving Teaching and Learning in Arusha City Public Secondary Schools, Tanzania}

\author{
Efraim N.M.Kosia \\ Ph.D. Candidate, Department of Education, Mwenge Catholic University, Tanzania \\ Dr. Evans Ogoti Okendo \\ Senior Lecturer, Department of Education, Mwenge Catholic University, Tanzania
}

\begin{abstract}
:
The study aimed at investigating the effects of School Quality Assurance Officers' feedback on improving teaching and learning in Arusha City Public secondary schools. The study was guided by the Utilization Focused Evaluation theory which assume the regardless how the evaluation processes and findings are, unless they are implemented to bring improvement, the evaluation is wastage of resources. The convergent parallel mixed method using concurrent approach with Ex-post Facto design case study designs were employed in the study. Data were collected from School Quality Assurance Officers, City Academic Officer, Ward Education Officers, and Heads of schools and teachers. Participants were selected using both probability and non-probability sampling procedures where data were collected using questionnaires, interview guides and focused group discussion. The findings of the study show that the overall quality of SQAOs is good in terms of quality, method used to gather feedback and degree of acceptability of feedback. Also, there is positive relationship between SQAOs feedback and improvement in teaching and learning in overall and in all school categories. However, feedback methods and feedback acceptability were the only factors with significant contribution on teaching and learning processes in all schools whereas, the SQAOs' models fit in all school categories.
\end{abstract}

Keywords: Feedback, school self evaluation, intended external evaluation effects

\section{Introduction}

School external evaluation as an evaluation process, is a systematic collection, analysis and interpretation of evidence leading, as part of the progression of judgement of value with a view of acting. External evaluation in most cases, focus more strongly on accountability dimension while on the other side it aims at giving feedback for the purpose of school improvement. According to Organization for Economic Cooperation and Development (OECD, 2013), SEE is considered as a review of the quality of education as it is judged by an external body or institutions. In this regard, school inspectors would be expected to assess, monitor and evaluate quality of school teaching and learning as well as assessing organization, management and environment of the school (United Republic of Tanzania (URT), 2011).

In various countries, including Tanzania, school inspectors spend days at school to conduct classroom observation where they assess classroom climate, teacher's mastery of subject content and teaching methodology where they are expected to discuss with the individual teachers on how the taught lesson could be improved. During the classroom observation, school inspectors usually focus on subject content, teaching learning methods, teaching aids and classroom control. School inspectors would facilitate school improvement on areas of teaching by giving feedback and advice to teachers after classroom observation. However, it has been observed that school inspectors do not get enough time to discuss the inspection findings with teachers compared to the head of schools (Haule, 2012). On the other side, in Tanzania, it has been observed that teachers in various schools tend to be dissatisfied with the school inspections exercise and its findings and recommendations. This scenario leaves the whole exercise on the cross road as far as the purpose of school inspection is concerned.

The school inspection system which does not create avenue for teachers to accept inspection findings is likely to bring no improvement in teaching and learning in schools. School inspectors need to create relationship with teachers and use sound communication style that would make teachers not only accepting feedback on their teaching but also use the findings to bring improvement in their teaching and learning approaches. Kambuga and Dadi (2015) found that school inspectors' visits to schools in Tanzania were insufficient and even the inspection findings and recommendations are poorly communicated to schools. In the report of Chief Auditor General of the United Republic of Tanzania it was found that School inspectors do not adequately compile inspection recommendations and even where they compile the findings, the recommendations of inspection feedback rarely have significance impact on school improvement (URT, 2008). Despite 
findings, the recommendation given was for inspectorate department to design the system which would maximize the use of inspection findings without what the design would entail.

\subsection{Research Questions}

- What are the levels of SQAOs' feedback in Arusha City Public secondary schools?

- What is the relationship between School Quality Assurance Feedback from SQAOs and improvement of teaching and learning Processes in Arusha City Public secondary schools?

- How does SQAOs' feedback contribute to improvement of teaching and learning in Arusha City Public secondary schools?

\subsection{Hypothesis}

- There is no significant relationship between SQAOs' Feedback and improvement of teaching and learning in Arusha City Public secondary schools.

- There is no significant contribution of SQAOs' Feedback on improvement of teaching and learning in Arusha City Public secondary schools.

\subsection{Conceptual Framework}

The School Quality Assurance Officers (SQAOs) visits schools to inspecting, advising and providing support to bring improvement in their schools. One of the major interactions with teachers is through classroom observation where they are required to provide feedback to individual teachers and school level on the strength and weakness identifies in the observation process. The conceptual framework on the effects of SQAOs' feedback used in this study assumes that the mechanism through which schools are given oral feedback, the quality of the feedback and the extent to which the school accepts feedback are important factors that can either lead to intended or unintended effects as a result of SQAOs' visit in a school. The intended effects of inspection on teaching and learning are assumed to be the extent to which schools continue implementing school's inspection findings some days after school quality assurance visits, whereas, on the other side, some teachers may play around SQAOs to hide the reality of the school so that they can be judged positively, consequently resulting to unintended effects.

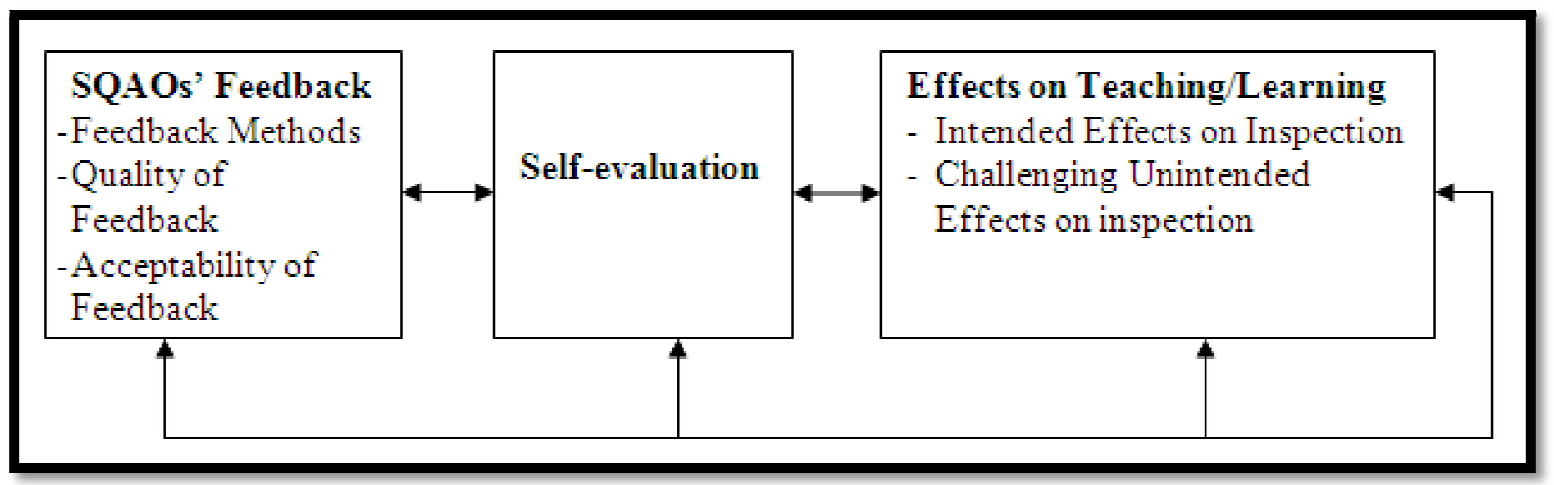

Figure 1: Effects of School Quality Assurance Officers' Feedback on Teaching and Learning Processes

According to the model, teachers who accept feedback would take actions on the given recommendations from SQAOs which subsequently lead to school improvement. Concurrently, SQAOs' should ensure that the mechanism used to give feedback as well as the quality of the feedback are prepared in the manner that will enhance the schools to not only accept the feedback but also use the feedback to bring improvement in the school. The School self-evaluation is intermediate factor that is expected to bridge the feedback and improvement in teaching and learning processes.

\section{Literature Review}

Quality means complying with expectations. People tend to view quality in terms of performance where quality is viewed as high grade or high status (IUCEA, 2010). A school can be said to be functioning optimally when it is providing good quality education in the sense of meeting expectations. The challenge with the issue of quality is the existence of various stakeholders who might be having different expectation from the school. For example, the government, the school board, parents, pupils, school management and the teaching staff of the school itself all have expectations on what should be attained from the school. However, studies show that sometimes, there is no evidence that issues agreed between school and inspectors after inspection. Ehren and Visscher (2008) found that number of improvement areas agreed between the inspectors and the school were laid down in the written report which were expected to be elaborated in an improvement plan ranged from 0 , where there were no agreements were made to an unknown number of appointments in other schools.

In order for school inspection to bring intended improvement in school, school inspection process should be tailored in the manner that optimize the potential of schools by ensuring that that schools find that the findings and recommendation given after inspection are not only valid but can be realistically implemented. The whole idea of how setting inspection standards influence school improvement is that if schools are given details which stipulated criteria and 
descriptors on the standard of performance expected of schools then schools will attempt to meet those expectations and subsequently they will have a positive impact on average (Jones and Tymms, 2014).

Standards is something used as a measure, norm or model of comparative evaluations (Oxford dictionary). A performance standard is a specific result or level of achievement that is deemed exemplary or appropriate. The word standard is sometimes used in education as a synonym for high expectations; at other times, a term standard is used as a synonym for benchmark (Vlăsceanu, Grünberg and Pârlea, 2007) and often one can also hear standards discussed in reference to the general guidelines or principles or criteria for judging performance.

Setting standards following an inspection from external school evaluators and other stakeholders of the school play both role of accountability and improvement dimension. Schools may be coerced into meeting inspection expectations when stakeholders or organizations upon which they are dependent exert formal or informal pressure on them to meet these expectations (Ehren et al., 2013). According to Jones and Tymms (2014), schools with set standards would be expected to rate themselves against standards as they complete the self-evaluation form but the accuracy of the form will enhance the capacity of schools to identify areas for improvement. A school that develops and implements the action plan is likely to result to expected improvement. On the other side as argued by Slavin (2005), some schools would improve only when there is external pressure to hold them responsible for their failure to meet standards. School inspectors should therefore set realistic performance standards with school and have mutual understanding of the targets for schools to be gauge against the same.

The inspection standards clarify clearly the criteria through which schools are expected to be evaluated. Despite that various countries have been found to use check lists that shows standards observed during inspection, it is have found that inspection a standardized tool can have a positive impact in relatively homogeneous environment but it may result to unintended effects if school have high disparities.

Jones and Tymms (2014) using Ofsted experience explained assumption regarding the influence of school feedback on school improvement. According to Jones and Tymms (2014), schools are likely to improve when they use the feedback given to them that clearly indicate their strengths and weaknesses. Schools inspections should endorse the schools' accurate own view of their effectiveness in order for the inspection process to lead to improved confidence which will in turn lead to school improvement. Conversely, where schools do not judge themselves accurately, the gap can rise between inspectors and school which can be a barrier for realization improvement in the school. Usually, Ofsted recommends priorities for future action and checks progress with the assumption that where it is deemed appropriate schools will generally improve. Where a constructive dialogue between inspectors and the senior leaders and staff of the school is established, there is more likelihood for the school to improve their teaching and learning conditions. However, the schools' improvement is also dependent on the school precise actions to underpin the identified recommendations (Jones and Tymms, 2014).

The pertinent observation in school inspection is on whether the method and data gathered during school inspection process provides an accurate assessment of the quality of a school. The invalid inspection data might lead to wrong judgments which may misguide administrative interventions and policy decisions and subsequently results to a negative impact on schools and teachers (Ehren, 2015a). In the situation where schools view that the school inspection feedback does not reflect the true picture of their performance there is more likelihood for school to reject the feedback.

It is imperative therefore that best evaluations should provide feedback about a school toward previously established goals or objectives; identify areas that require further attention or improvement; and identify areas of excellence but at the same time strengthening commitment to efforts and processes that are expected to producing positive results (Mann and Smith, 2013). Regardless mechanism and how good the feedback is assumed to be, accepting feedback is a key to successful action taken towards implementation of the inspection findings and recommendation. Accepting feedback may represents the degree to which the schools perceives the feedback received from inspectors as insightful and useful, and the extent to which they might be prepared to act on it (Gustafson et al., 2015). The study shows that findings and recommendations of the school inspectors have not been addressed by the inspected schools. The school where both external and school self-evaluation is conducted, the findings from the two sources may not tally. Studies show that the school inspectors in such situation claim that school often gave themselves high scores.

\section{Methodology}

The study on the effects of SQAOs' Feedback on teaching and learning processes used the convergent parallel mixed methods design through concurrent approach to gather data from both qualitative and quantitative approaches in order employed to address the three research questions and two hypotheses. Participants in the research were classroom teachers, Heads of schools, Ward Education officers, City Academic Officers and North-West zone SQAOs. Data were collected from the area which was under on study on implementation of school quality assurance which was new direction for implementation of school inspection in Tanzania. In the study, school inspectors had provided support for some schools to establish school self-evaluation as a way of shifting from inspection role quality assurance approach. As such, one school under the study was purposely sampled as treatment school whereas, other 8 schools which were sampled using probability sampling procedures for the purpose of comparing with the treatment school. The 8 schools composed of 3 low performing and 5 high performing schools for the purpose of comparing on whether being high or low performing school had an effect on the SQAOs' feedback as predictor of improvement in teaching and learning. It was not possible to include more treatment schools in the study because only one school had effectively implemented school's self-evaluation in the area under the support of SQAOs. The researcher used questionnaires; interview guides and focused group discussion were used for data collection on effects of SQAOs' feedback on teaching and learning in Arusha City Public secondary schools. 


\section{Results}

This research study aimed at establishing the relationships between School Quality Assurance Officers' feedback and the implementation of findings and recommendations on teaching and learning processes. In order to establish the relationship, the researcher computed correlation coefficient and regression analysis from the questionnaire. Correlation to establish the extent to which the feedback given to schools predict the improvement on teaching and learning processes.

\subsection{Levels of School Quality Assurance Officers' Feedback in Arusha City Secondary Schools}

This section present means and standard deviations on quality of feedback given to schools, methods used by SQAOs in giving feedback and the extent to which schools accept feedback given to them by quality assurance officers. Fourteen items were used to construct the quality of feedback, comprising of 7 on quality oral feedback and the other 7 on written feedback. The descriptive statistics results on oral feedback, written feedback, methods used by SQAOs in providing feedback and the extent to which schools accepted feedback from SQAOs are presented in Table 1.

\begin{tabular}{|c|c|c|c|c|}
\hline \multirow{2}{*}{ SQAOs' Feedback } & \multicolumn{4}{|c|}{ Categories of Schools (N= 166) } \\
\cline { 2 - 5 } & $\begin{array}{c}\text { All Schools } \\
(\mathrm{N}=166)\end{array}$ & $\begin{array}{c}\text { Treatment School } \\
(\mathrm{n}=20)\end{array}$ & $\begin{array}{c}\text { Low Performing Schools } \\
(\mathrm{n}=48)\end{array}$ & $\begin{array}{c}\text { High Performing Schools } \\
(\mathrm{n}=98)\end{array}$ \\
\hline Quality of Feedback & 3.54 & 3.79 & 3.58 & 3.50 \\
\hline Feedback Methods & 3.39 & 3.20 & 3.43 & 3.42 \\
\hline $\begin{array}{c}\text { Feedback } \\
\text { Acceptability }\end{array}$ & 3.39 & 3.07 & 3.44 & 3.43 \\
\hline Feedback & 3.47 & 3.30 & 3.52 & 3.47 \\
\hline
\end{tabular}

Table 1: Means Levels of Feedback from SQAOS in Treatment, Low and High Performing Schools Note: The Feedback Used by SQAOs is Worst When $1 \leq \mathrm{M}<2$, Bad When $2 \leq \mathrm{M}<3$, Moderate When $3 \leq \mathrm{M}<4$, Good When $3<\mathrm{M} \leq 4$ and Very Good When $4<\mathrm{M} \leq 5$

Results in Table 1 indicate that the SQAOs' feedback was generally perceived as by teachers with a range from $\mathrm{M}=3.30$ treatment to $\mathrm{M}=3.52$ in low performing schools. In the same vein, teachers perceived that the SQAOs' quality of oral and written feedback, methods used in giving feedback to schools and levels of acceptability of feedback were good. Therefore, Correlation coefficients were computed to find whether there was relationship between SQAOs' Feedback and the level of implementation of Teaching and Learning findings and Recommendations in all schools and three categories of schools.

The interview results received from the head of school indicated that SQAOs do give both oral and written feedback. The SQAOs had to meet the head of school before meeting the management at large, the one of the head of schools indicated that the feedback received from on individual teachers only addressed on the negative areas. The head explained as follows:

"... I do receive feedback for individual teachers on the negative but not the positive one; if the SQAOs give me few negatives I assume that my teachers have more of the positive than negative. If they seat with my teachers discuss and finish as expected I do not hear the word. However, on the final report they talk the positives and negatives" (Interview, 2018).

The above results from qualitative data show that there is less emphasize on the positive findings compared to the negatives. Less emphasize on the positive side is likely to create teachers who might have less innovation than compliance attitude.

4.2. The Correlation between SQAOs' Feedback and Implementation of Teaching and Learning Findings and Recommendations Various Schools

The Correlation between SQAOs' Feedback and implementation of Teaching and Learning findings and Recommendations in All schools and three categories of schools was established from teachers' questionnaire. The following hypothesis was tested:

- Null hypothesis $1\left(\mathrm{H}_{0}\right)$ : There is no Significant Relationship between SQAOs' Feedback and Improvement of

Teaching and Learning Processes in different School Categories.

The correlation coefficients on the relationship between SQAOs' Feedback and the levels of implementation of Teaching and Learning findings and Recommendations in all schools and three categories of schools are presented in Table 2. 


\begin{tabular}{|c|c|c|c|c|}
\hline Sqaos' Feedback & \multicolumn{4}{|c|}{ Improvement in Teaching and Learning Process (N= 166) } \\
\hline & $\begin{array}{c}\text { All Schools } \\
(\mathrm{N}=166)\end{array}$ & $\begin{array}{c}\text { Low Performing Schools } \\
(\mathrm{n}=48)\end{array}$ & $\begin{array}{c}\text { High Performing } \\
\text { Schools }(\mathrm{n}=98)\end{array}$ & $\begin{array}{c}\text { Treatment School } \\
(\mathrm{n}=20)\end{array}$ \\
\hline Quality of Feedback & $433^{* *}$ & .191 & $.498^{* *}$ & $.599^{* *}$ \\
\hline Feedback Methods & $.489^{* *}$ & $.388^{* *}$ & $.488^{* *}$ & $.695^{* *}$ \\
\hline Feedback Acceptability & $.520^{* *}$ & $.368^{* *}$ & $.521^{* *}$ & $.726^{* *}$ \\
\hline Overall Feedback & $.519^{* *}$ & $.329^{*}$ & $.547^{* *}$ & $.697^{* *}$ \\
\hline
\end{tabular}

Table 2: Correlation Coefficient between SQAOs' Feedback and Improvement in Teaching and Learning Processes in

Treatment, Low and High Performing Schools

* Correlation Is Significant at the 0.05 Level (2-Tailed)

**. Correlation Is Significant at the 0.01 Level (2-Tailed)

Results in Table 2 indicate that when school were nested together and in high performing schools, the significant relationship between quality of feedback and the level of implementation of findings and recommendations on teaching and learning processes was found ranging from .433 to .520 . This show that all the three-variable had moderate significant relationship with improvement in teaching and learning. As a rule of thumb, a correlation coefficient between $0-0.3$ is regarded a weak, correlation coefficient higher than 0.3 - 0.6 is regarded as moderate whereas correlation coefficient above 0.6 is regarded as strong (Connolly, 2007).

In low performing schools, moderate significant relationship was found between improvement of teaching and learning and both adequacy of methods used to give feedback ( $(48)=0.388, p<0.01)$ and acceptability of feedback $(r$ $(48)=0.368, p<0.01$ ) while not significant relationship was found with quality of feedback $(r(48)=0.191, p>0.05)$. In Treatment, strong significant relationship ranging from 0.599 (estimated to 0.6) on quality of feedback to 0.726 on acceptability of feedback.

In Table 2, when all variable was combined to make variable of SQAOs' feedback, except the in a Treatment school which showed high relationship $(\mathrm{r}(20)=0.697, \mathrm{p}<0.01$ ) between SQAOs' feedback and teaching and learning, in all other school categories and when schools were nested together, moderate relationships ranging from 0.329 to 0.547 .

4.3. Regression Analysis of Effectiveness of SQAOs' Feedback on Implementation of Findings and Recommendations on Teaching and Learning Processes

This section presents the findings on regression analysis of effectiveness of SQAOs' feedback as predictors of implementation of teaching and learning findings and recommendations. Findings are presented based on the beta values, t-values, R, $\mathrm{R}^{2}$ and ANOVA at all schools combined together and based on school categories as units of measure to display four models in (4) Models in Table 3.

\begin{tabular}{|c|c|c|c|c|c|c|c|c|}
\hline \multirow[t]{2}{*}{ Measure } & \multicolumn{2}{|c|}{$\begin{array}{c}\text { All Schools } \\
\text { Model } 1\end{array}$} & \multicolumn{2}{|c|}{$\begin{array}{c}\text { Low Performing } \\
\text { Model } 2\end{array}$} & \multicolumn{2}{|c|}{$\begin{array}{c}\text { High Performing } \\
\text { Model } 3\end{array}$} & \multicolumn{2}{|c|}{$\begin{array}{l}\text { Treatment } \\
\text { Model } 4\end{array}$} \\
\hline & Beta & t-value & Beta & t-value & Beta & t-value & Beta & t-value \\
\hline Constant & .749 & $2.122 *$ & 1.157 & 1.300 & .782 & 1.710 & .081 & .093 \\
\hline $\begin{array}{l}\text { Quality of } \\
\text { Feedback }\end{array}$ & .055 & .399 & -.152 & -.592 & .220 & 1.030 & -.062 & -.200 \\
\hline Feedback Methods & .308 & $2.148^{*}$ & .507 & 1.471 & .239 & 1.354 & .520 & 1.179 \\
\hline $\begin{array}{c}\text { Feedback } \\
\text { Acceptability }\end{array}$ & .452 & $3.187^{* *}$ & .315 & 1.021 & .361 & 1.815 & .576 & 1.530 \\
\hline $\mathrm{R}$ & \multicolumn{2}{|c|}{$.546^{\mathrm{a}}$} & \multicolumn{2}{|c|}{$.422^{\mathrm{c}}$} & \multicolumn{2}{|c|}{$.553^{\mathrm{a}}$} & \multicolumn{2}{|c|}{$.752^{\mathrm{d}}$} \\
\hline $\mathrm{R}^{2}$ & \multicolumn{2}{|c|}{$\begin{array}{c}.298 \\
1694\end{array}$} & \multicolumn{2}{|c|}{.178} & \multicolumn{2}{|c|}{.305} & \multicolumn{2}{|c|}{.565} \\
\hline Durbin-Watson & \multicolumn{2}{|c|}{1.694} & \multicolumn{2}{|c|}{1.661} & \multicolumn{2}{|c|}{1.578} & \multicolumn{2}{|c|}{1.578} \\
\hline ANOVA & \multicolumn{2}{|c|}{$\begin{array}{c}F(3,162)=22.966 \\
p=.000\end{array}$} & \multicolumn{2}{|c|}{$\begin{array}{c}\mathrm{F}(3,44)=3.169 \\
\mathrm{p}=034\end{array}$} & \multicolumn{2}{|c|}{$\begin{array}{c}\mathrm{F}(3,94)=13.779 \\
\mathrm{p}=.000\end{array}$} & \multicolumn{2}{|c|}{$\begin{array}{c}\mathrm{F}(4,15)=6.939 \\
\mathrm{p}=.003\end{array}$} \\
\hline
\end{tabular}

Table 3: Regression Models of Feedback Models as Predictors of Implementation of Teaching and Learning Recommendations

*. Significant at the 0.05 Level

**. Significant at the 0.01 Level

Durbin-Watson Test results presented in Table 3 ranged from 1.589 to 1.694 which is within the acceptable range between 1 and 3, explaining that independent errors assumption of regression analysis was met for all three models (Field, 2013). Also, Field (2013) classified that the effect is small, medium and large when the coefficient of coefficient is $0.10(1 \%), 0.30(9 \%)$ and $0.50(25 \%)$; respectively.

Results of regression analysis when schools were nested together in Model 1 of Table 3 showed that the Quality of oral feedback, quality of written feedback, methods used to give feedback to school and the extent of acceptability of feedback explained $29.8 \%$ of the variations $\left(\mathrm{R}^{2}=0.298, \mathrm{~F}(3,162)=22.966, \mathrm{p}<000\right)$ which suggest that the school evaluation model for school nested together had large effect on improvement of teaching and learning processes. It was also found that both feedback methods $(\beta=0.308, p<0.05)$ and acceptability of feedback $(\beta=0.452, p<0.01)$ significantly 
predicted improvement in teaching and learning processes. While quality of written feedback had positive non-significant effect, the quality of oral feedback had negative non-significant effect $(\beta=0.055, p>0.05)$.

- Improvement in Teaching and Learning Processes $=0.749+0.055^{*}$ Quality Feedback + $0.308 *$ Feedback Methods $+0.452 *$ Acceptability of Feedback

In low performing schools (Model 2), results of the regression analysis indicated that the model explained $17.8 \%$ of the variations and that the model was a significant predictor of the improvement of teaching and learning $\left(\mathrm{R}^{2}=0.178, \mathrm{~F}(3,44)=3.169, \mathrm{p}>051\right)$. Therefore, these results suggest that the school evaluation model in low performing schools, though not significant, had medium effect on improvement of teaching and learning processes. Field (2013) classified that the effect is small, medium and large when the coefficient of coefficient is $0.10(1 \%)$, 0.30 (9\%) and 0.50 (25\%); respectively. Results also showed that though the Model 2 had no significant effect on feedback features as predictors of, the Model had non-significant effect on oral feedback of improving teaching and learning processes as presented in Table 3. The final predictive model of internal school features on improvement in teaching was:

- Improvement in Teaching and Learning Processes $=1.250-0.304^{*}$ Quality of Feedback + $0.499 *$ Feedback Method $+0.305 *$ Acceptability of Feedback

In Model 3 which presented the regression analysis in high performing schools indicated that the model explained $30.5 \%$ of the variations and that the model was a significant predictor of improvement in teaching and learning processes $\left(R^{2}=0.308, F(3,94)=13.779, p<001\right)$. These results suggest that the school evaluation model in high performing schools had large effect on improvement of teaching and learning processes. It was also found that none of the predictors showed significantly contribution to the model. The predictive model was:

- Improvement in Teaching and Learning Processes $=0.782+0.220 *$ Quality of Feedback + $0.239 *$ Feedback Method $+0.361 *$ Acceptability of Feedback

Results showed that Model 4 in Treatment school explained 56.5\% of the variance and that the model was a significant predictor of improvement of teaching and learning processes $\left(R^{2}=0.565, F(3,16)=6.939, p<001\right)$. Though was also found that none of the predictors showed significantly contribution to the model like in high performing school, quality of written feedback showed non-significant negative contribution to the model. The final predictive model of internal school feedback on improvement in teaching in Treatment school was:

- Improvement in Teaching and Learning Processes $=0.081-0.062 *$ Quality of Feedback + $0.520 *$ Feedback Methods $+0.576 *$ Acceptability of Feedback

Generally, the school inspection of feedback as predictor of improvement in teaching and learning processes when schools are nested together show that feedback methods and feedback acceptability significantly contribute to teaching and learning. While, no significant production was observed in other school categories. The quality of feedback had no significant effect on teaching and learning in all school categories and when schools were nested together. However, though not significant negative effects were found in both low performing and treatment school, which suggest that the feedback quality provided by SQAOs in these school categories may not fit well the models.

These findings are different from those reported by Ehren et al. (2015) who tested on the extent to which differentiated inspections, use of outcome, sanctions and public reporting inspection models had effects on accepting of feedback as a predict of school improvement. Ehren et al. (2015) found that among the four models, except Public reporting model, other models had negative effects on acceptability of feedback. In the current study, acceptability of feedback had non-significant positive effect on improvement in low performing, high performing and Treatment schools. On the other hand, the current findings are contrary to those found in the three-year research project which involved primary and secondary school in Austria. In the research, Altrichter and Kemethofer (2014) found weak relationship between acceptability of feedback and improvement in school $.098(\mathrm{p}=0.115), 0.047(\mathrm{p}=484)$ and $0.083(\mathrm{p}=268)$ in year 1, 2 and 3, respectively.

These findings suggest that models may have promising results on the extent to which feedback methods and acceptability would predict implementation of findings and recommendations of teaching and learning processes. However, though not significant, quality of oral and written feedback is likely to have negative effective on the improvement of teaching and learning in low performing schools. Moreover, while the current inspection model does in high performing and Treatment schools, the current inspection model does not fit in the low performing schools.

\section{Conclusion and Recommendations of the Study}

The research results and findings have indicated that the SQAOs give good feedback to teachers as judged in terms of the method used in delivering feedback, the quality of feedback and the degree to which schools accepts feedback for use. In the same vein, there is significant relationship between the SQAOs' visits as a result of inspection visits.

Though the SQAOs' feedback fit the model in schools' categories, the model explained largest effects in a Treatment school and least effects in low performing schools. However, the models explained large effects in both Treatment and high performing schools but medium effects in the low performing schools. Both Methods of giving feedback and feedback acceptability had positive contribution on teaching and learning which was significant when all schools were nested together whereas, though not significant, quality of feedback has negative contribution on teaching and learning in low and treatment schools.

The research recommends more research to be conducted in the setting that segregate high and low performing schools using large number of schools in treatment group to gain more evidence on the effects of self-evaluation in fitness in low performing schools and high performing schools. 


\section{References}

i. Altrichter, H., \& Kemethofer, D. (2015). Does accountability pressure through school inspections promote school improvement? School Effectiveness and School Improvement, 26 (1), 32-56.

ii. Connolly, P. (2007). Quantitative Data Analysis in Education: A critical Introduction using SPSS. Taylor \& Francis e-Library, London \& New York.

iii. Ehren M. C. M., Altrichter, H., McNamara, G., \& J. O'Hara (2013). Impact of school inspections on improvement of schools-describing assumptions on causal mechanisms in six European countries. Educational Assessment Evaluation and Accountability, 25, 3-43. DOI 10.1007/ s11092-012-9156-4.

iv. Ehren, M. C. M. (2015a). Emerging Models of School Inspections: Shifting Roles and Responsibilities. In Melanie C.M. Ehren (Editor): Methods and Modalities of Effective School Inspections. Springer International Publishing House, Switzerland.

v. Ehren, M. C. M., \& Visscher, A. J. (2008). Towards on a Theory on the Impact of School Inspections. British Journal of Education Studies, 1, 51-72.

vi. Field, A. (2013). Discovering Statistics using IBM SPSS Statistics. SAGE Publications India Ltd.

vii. Gustafsson, J. E., Ehren, M. C. M., Conyngham, G., McNamara, G., Altrichter, H., \& O’Hara, J. (2015). From inspection to quality: Ways in which school inspection influences change in schools. Studies in Educational Evaluation, 47, 47-57.

viii. Haule, M. E. (2012). The Perceptions of School Teachers and Leaders toward School Inspections in Tanzania Secondary Schools: The Case of Arusha Municipality (Master's Thesis). University of Twente, Enschede, the Netherlands.

ix. IUCEA (2010). A Road Map to Quality: Handbook for Quality Assurance in Higher Education. Volume 2: Guidelines for External Assessment at Program Level. The Inter-University Council for East Africa/ DAAD 2010.

x. Jones, K. L., \& Tymms, P. B. (2014) 'Ofsted's role in promoting school improvement: the mechanisms of the school inspection system in England. Oxford Review of Education, 40 (3), 315-330.

xi. Kambuga, Y., \& Dadi, H. (2015). School inspection in Tanzania as a motor for education quality: Challenges and possible way forward. Review of Knowledge Economy, 2 (1), 1-13.

xii. Mann, M. J., \& Smith, M. L. (2013). Promoting Rigor-in- Practice through School Self-Evaluation: A Middle School's Experience with Model Development, Implementation, and Evaluation, RMLE Online, 37 (4), 1-15

xiii. OECD. (2013). "School evaluation: From compliancy to quality", in Synergies for Better Learning: An International Perspective on Evaluation and Assessment, OECD Publishing.

xiv. Slavin, R. E. (2005). Sand, Bricks, and Seeds: School Change Strategies and Readiness for Reform. D. Hopkins (Ed.). The Practice and Theory of School Improvement, 265-279. ( $) 2005$ Springer. Printed in the Netherlands.

xv. URT. (2008). A Performance Audit Report on Inspection Programme for Secondary Schools in Tanzania: A report of The Controller and Auditor General of the United Republic of Tanzania. National Audit Office, Dar es Salaam. http:/ / www.nao.go.tz.

xvi. URT. (2011). School's Supervisor's Training Manual. Ministry of Education and Vocational Training, Dar es Salaam.

xvii. Vlăsceanu, L., Grünberg, L., \& Pârlea, D. (2007). In (Editors: Melanie Seto, Peter J. Wells) Quality Assurance and Accreditation: A Glossary of Basic Terms and Definitions. Revised and Updated Edition UNESCO-CEPES 2007. 